\title{
Strains in Thermally Growing Alumina Films Measured In-situ Using Synchrotron X-rays
}

\author{
P. Y. Hou ${ }^{1, a}$, A. P. Paulikas ${ }^{2, b}$ and B. W. Veal ${ }^{2, c}$ \\ 1 Lawrence Berkeley National Lab., 1 Cyclotron Rd. MS: 62-203, Berkeley, CA 94530, USA \\ ${ }^{2}$ Argonne National Lab., 9700 S. Cass Ave., Chicago, IL, 60439, USA. \\ apyhou@lbl.gov, ${ }^{b}$ paulikas@anl.gov, veal@anl.gov
}

Keywords: $\mathrm{x}$-ray diffraction, $\mathrm{Al}_{2} \mathrm{O}_{3}, \mathrm{Cr}_{2} \mathrm{O}_{3}$, growth stress, oxide creep

\begin{abstract}
Strains in thermally grown oxides have been measured in-situ, as the oxides develop and evolve. Extensive data have been acquired from oxides grown in air at elevated temperatures on different model alloys that form $\mathrm{Al}_{2} \mathrm{O}_{3}$. Using synchrotron $\mathrm{x}$-rays at the Advanced Photon Source (Beamline 12BM, Argonne National Laboratory), Debye-Scherrer diffraction patterns from the oxidizing specimen were recorded every 5 minutes during oxidation and subsequent cooling. The diffraction patterns were analyzed to determine strains in the oxides, as well as phase changes and the degree of texture. To study a specimen's response to stress perturbation, the oxidizing temperature was quickly cooled from 1100 to $950^{\circ} \mathrm{C}$ to impose a compressive thermal stress in the scale. This paper describes this new experimental approach and gives examples from oxidized $\beta$-NiAl, Fe-20Cr-10Al, Fe-28Al-5Cr and $\mathrm{H}_{2}-$ annealed $\mathrm{Fe}-28 \mathrm{Al}-5 \mathrm{Cr}$ (all at. \%) alloys to illustrate some current understanding of the development and relaxation of growth stresses in $\mathrm{Al}_{2} \mathrm{O}_{3}$.
\end{abstract}

Introduction. The existence of a growth stress associated with oxidation has long been envisioned [1], since most oxides have higher volumes than their corresponding metals. Later, it was proposed that growth stress can arise from oxide formation within the scale as the diffusing cations and anions meet and react, particularly along oxide grain boundaries [2]. Several other mechanisms have also been proposed to explain the origin of growth stresses [3]; however, actual in-situ measurements of these stresses are scarce. Values are usually deduced from the difference between measured residual stresses at room temperature and the calculated thermal stress based on thermal expansion coefficients (CTE) of the oxide and the alloy. However, this method depends on CTE values, which are often unreliable, cannot properly account for stress relaxations and fails to follow the development of growth stresses with time.

Among the limited experimental efforts to determine the magnitude of oxidation stresses insitu are deflection [4-6] and x-ray diffraction [7-9] techniques. The former makes use of an asymmetrical specimen that is long and thin with a protective layer on one side to prevent one face of the specimen from oxidizing. Any stress generated from oxidation of the bare surface, therefore, will cause the specimen to deflect. The direction and degree of deflection give an indication of the sign and magnitude of the growth stress respectively. The technique, however, relies on a protective layer that cannot fully stop oxidation at elevated temperatures. Furthermore, analysis of the stress level is complicated by the visco-elastic response of the alloy at high temperatures [10]. X-ray diffraction, especially the $\sin ^{2} \psi$ method, is a well known and proven method for stress measurements. The challenge is to perform the experiment at elevated temperatures with sufficiently high accuracy and precision and sufficiently fast response time.

In this paper, a novel x-ray technique (a variant of the $\sin ^{2} \psi$ method) is described, where the elliptical distortion of Debye-Scherrer diffraction rings is measured for all accessible $\psi$ angles to obtain the in-plane strain. In-situ measurements were performed with synchrotron radiation at beamline 12BM at the Advanced Photon Source at Argonne National Laboratory. Some results 
are presented to illustrate a few important issues concerning the development and relaxation of stresses during oxide growth.

Experimental. Fig. 1(a) shows a simple schematic of the experimental setup. The test sample is positioned on a thin alumina shelf, cemented into an open ended horizontal tube furnace. A Type S Pt-Pt(Rh) thermocouple (TC), whose temperature was calibrated by melting a gold foil in the sample position, was placed under the shelf, immediately beneath the sample. The sample surface is usually polished to a $1 \mu \mathrm{m}$ finish using diamond slurry. During the test, a $21.6 \mathrm{keV} \mathrm{x}$ ray beam, with a spot size of about $0.1 \mathrm{~mm}(\mathrm{FWHM}) \times 1 \mathrm{~mm}$, strikes the sample surface at an incidence angle of 2 to $5^{\circ}$. Half circles of Debye-Sherrer diffraction rings from the sample are recorded using an image plate detector; an example of these half rings is shown in Fig. 1(b). For precise determination of the x-ray scattering center, and any detector misorientation, a porous, sintered alumina sheet is used as a reference sample. The reference is placed into the x-ray path, using a pneumatic actuator, after the test specimen is lowered. The $\mathrm{x}$-rays penetrate through this thin reference and yield full-circle diffraction spectra (Fig. 1(c)) that can be analyzed to obtain the location of the beam centroid to within $\pm 2 \mu \mathrm{m}$. The reference and sample motions are computer driven; typically, a reference spectrum is recorded after five successive sample measurements, each of 5 minutes duration.
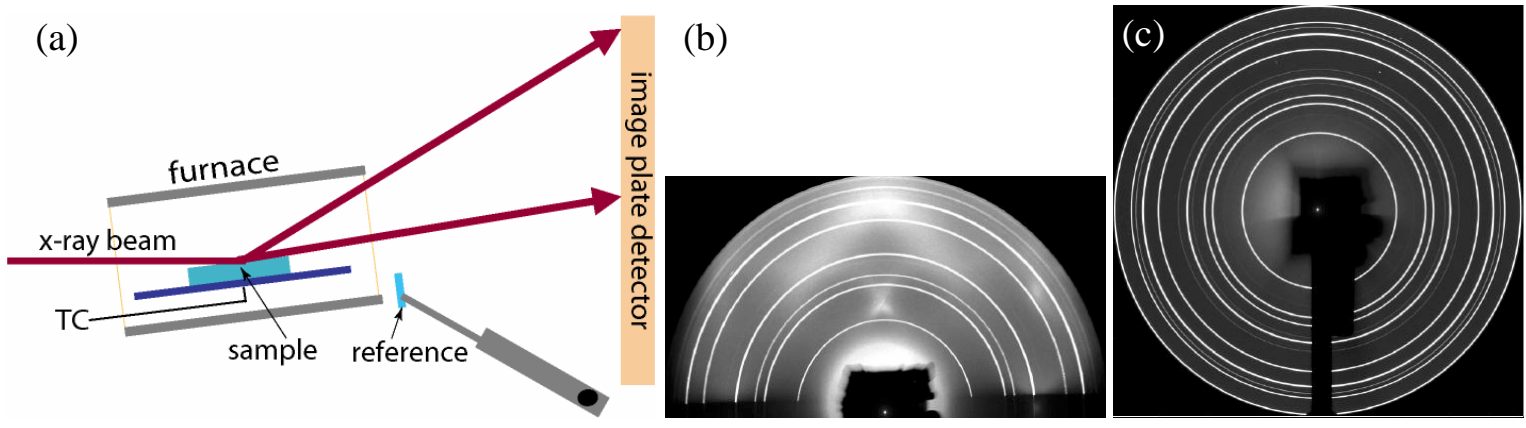

Figure 1: (a) Schematic of the experimental setup. (b) Half rings of $\alpha-\mathrm{Al}_{2} \mathrm{O}_{3}$ reflections from a NiAl sample. (c) Full $\alpha-\mathrm{Al}_{2} \mathrm{O}_{3}$ Debye-Scherrer rings from the alumina reference.
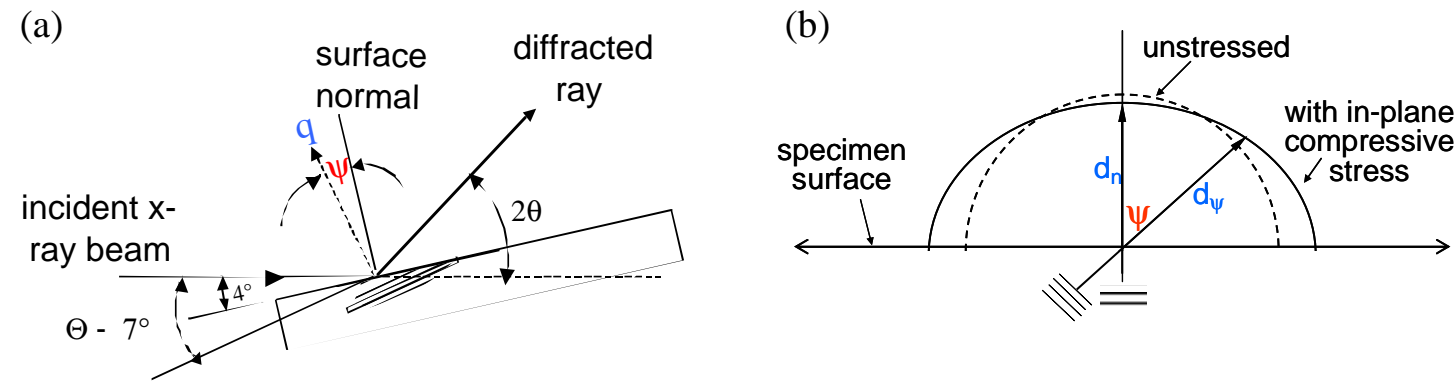

Figure 2: Schematic illustrations of (a) diffraction geometry and (b) response of a Debye-Sherrer diffraction ring under a compressive in-plane stress.

The technique is a single exposure method, where diffraction rings from all diffracting planes that are accessible in the experimental geometry are recorded. All accessible $\psi$ angles $(\sim$ $\left.7-75^{\circ}\right)$ are simultaneously acquired for each ring. As shown in Fig. 2(a), $\psi$ is the angle between the sample normal and the x-ray scattering vector. Since in-plane and out-of-plane d-spacings of diffracting planes in a stressed film are different, the resulting Debye-Scherrer rings are elliptically distorted, as illustrated in Fig. 2(b). This ellipticity is measured and analyzed to determine the strain in the film. With conventional tilting methods, measurements are typically acquired at only a few $\psi$ angles in the Debye-Scherrer pattern. The ability to obtain data from a 
continuous range of $\psi$ angles in the current method not only provides high precision, but also reveals texture, if it exists, and shows the location of any diffraction rings or peaks from substrate grains. The diffraction pattern can also reveal the oxide phases and phase transformations that are present during an oxidation run. Slurries of $\mathrm{Al}_{2} \mathrm{O}_{3}$ and $\mathrm{Cr}_{2} \mathrm{O}_{3}$ powders applied on different substrates have been used as test samples at temperatures up to $1100^{\circ} \mathrm{C}$ to verify the position of zero strain. Five such tests have been run and the results show a zero strain level better than $\pm 20 \mathrm{MPa}$.

Specimens were heated at a linear rate of $1000^{\circ} \mathrm{C} / \mathrm{hr}$ and oxidized at $1000-1100^{\circ} \mathrm{C}$ in ambient air. Sometimes during isothermal oxidation, the temperature would be lowered by $50-150^{\circ} \mathrm{C}$ to introduce a thermal stress, such that relaxation of this stress could be followed. After oxidation, the samples were furnace cooled and the stress level during cooling continued to be recorded. Observations of scale morphology were performed using high resolution SEM after the strain tests.

Strain Analysis. To obtain the in-plane strain for a given ring, the entire 3-dimensional diffraction pattern, for that ring is fitted to obtain $d_{\psi}$, the $\psi$-dependent $d$-spacing. For an oxide film under a biaxial stress that is isotropic, experiencing no shear, it can be shown [11], that

$$
\mathrm{d}_{\psi}=\mathrm{d}_{0}\left[1+\left(\varepsilon_{11}-\varepsilon_{33}\right) \sin ^{2} \psi+\varepsilon_{33}\right]
$$

where $\mathrm{d}_{0}$ is the unstrained lattice parameter and $\varepsilon_{11}$ and $\varepsilon_{33}$ are the in-plane and out-of-plane strain components respectively. We express Eq (1) as

$$
\mathrm{d}_{\psi}=\mathrm{d}_{\mathrm{est}}\left[1+\mathrm{A} \sin ^{2} \psi+\mathrm{B}\right]
$$

and treat $A$ and $B$ as fitting parameters. (A value is assigned to $d_{\text {est }}$, usually a published value of the lattice parameter, although, as we show below, the choice of this value has no influence on the measured in-plane strain.) These are constants for a particular ring and specific value of inplane strain. Thus, in the fitting operation, chosen (trial) values of A and B (and other fitting parameters) are used to calculate $d_{\psi}$ for all measured values of $\psi$. The calculated $d_{\psi}$ are then used in the diffraction equation

$$
\theta_{0}=\sin ^{-1}\left[\lambda /\left(2 d_{\psi}\right)\right]
$$

to obtain, for all measured $\psi$, the term $\theta_{0}$, the $\psi$ dependent centroid of the diffraction ring. The intensity of the ring, $\mathrm{I}_{\theta}$, is given by

$$
\mathrm{I}_{\theta, \psi}=\mathrm{I}_{\mathrm{b}}+\mathrm{C} f \exp \left(2 \theta-2 \theta_{\mathrm{o}}\right)^{2} / 2 \mathrm{w}^{2}
$$

where $\mathrm{I}_{\mathrm{b}}$ is the background intensity and $\mathrm{w}$ and $\mathrm{C}$ are, respectively, its Gaussian width and amplitude; $\mathrm{f}$ is an experimental parameter formulated to include effects of absorption, $\mathrm{x}$-ray beam polarization and sample texture. The parameters $\mathrm{I}_{\mathrm{b}}, \mathrm{w}, \mathrm{C}$ and parameters in the functions $\mathrm{f}$ are all $\psi$ dependent.

In the fitting routine [commercial software IGOR, by WaveMetrics, Inc.], A, B, and all additional fitting parameters are iteratively adjusted until convergence is achieved, that is, until no significant improvement in the fit is achievable with additional adjustment of the parameters. From Eqs. (1) and (2), it follows that

$$
\mathrm{D}=\left(\mathrm{d}_{\psi=90^{\circ}}-\mathrm{d}_{\psi=0^{\circ}}\right) / \mathrm{d}_{\psi=0^{\circ}}=\mathrm{A} /(1+\mathrm{B})=\left(\varepsilon_{11}-\varepsilon_{33}\right) /\left(1+\varepsilon_{33}\right)
$$

For an elastically homogeneous distribution of crystallites in a biaxially stressed film with no shear $\left(\sigma_{11}=\sigma_{22}, \sigma_{33}=0\right.$ and $\left.\sigma_{12}=\sigma_{13}=\sigma_{23}=0\right)$,

$$
\begin{array}{ll}
\varepsilon_{11}=(1-v) \sigma_{11} / \mathrm{Y} & \text { Eq. (6) } \\
\varepsilon_{33}=-2 v \sigma_{11} / \mathrm{Y} & \text { Eq. (7) }
\end{array}
$$


where $v$ is the Poisson's ratio for the oxide, $\sigma_{11}$ the in-plane stress and $Y$ the Young's modulus for the film [11]. Combining equations (5) - (7), the in-plane strain can be expressed as

$$
\varepsilon_{11}=\mathrm{D}(1-v) /(1+v+2 v \mathrm{D}) \sim \mathrm{D}(1-v) /(1+v)
$$

For $\alpha-\mathrm{Al}_{2} \mathrm{O}_{3}, v=0.25$ [12] and $\mathrm{Y}=380 \mathrm{GPa}$ [12] so that $\varepsilon_{11} \sim 0.6 \mathrm{D}$. In-plane stress is then obtained from Eq. (6). For any given sample, multiple lines of the diffraction spectrum are usually analyzed independently to obtain the in-plane strain. The average value is used to obtain $\sigma_{11}$. Importantly, these independent measurements of $\varepsilon_{11}$ provide a valuable consistency check on the analysis routine. Note that, in Eq. (2), any error in $d_{\text {est }} \sim d_{0}$ will appear as a compensating error in $\mathrm{A}$ and in $(1+\mathrm{B})$. However, $\mathrm{D}$ is expressed as the ratio $\mathrm{A} /(1+\mathrm{B})$, and is therefore independent of $\mathrm{d}_{0}$.

\section{Results and Discussion}

Transformation stresses in $\mathbf{A l}_{2} \mathbf{O}_{3}$. When an $\mathrm{Al}_{2} \mathrm{O}_{3}$ forming alloy is oxidized, a transition alumina film generally develops first, and it later transforms to the thermally most stable $\alpha$ $\mathrm{Al}_{2} \mathrm{O}_{3}$. These transition aluminas have been identified to be either the $\theta$ [13-16] or the $\gamma$ phase [17-19]. They grow 1-2 orders of magnitude faster than $\alpha-\mathrm{Al}_{2} \mathrm{O}_{3}$ [14,20], and the growth is dominated by aluminum outward transport [21]. For oxidized nickel-aluminides, transformation to the alpha form starts at the scale/alloy interface as circular patches that spread laterally until a complete layer of $\alpha-\mathrm{Al}_{2} \mathrm{O}_{3}$ becomes established at the scale/alloy interface [15-17]. At this time, the oxidation rate becomes dominated by the slow growth of this alpha layer, which is achieved mainly by anion transport [21]. Eventually, all of the initially formed $\gamma$ and/or $\theta$ aluminas transform to the $\alpha$ phase. A volume contraction of $\sim 5-8 \%$ [12] is associated with this transformation, which can put the first-formed $\alpha-\mathrm{Al}_{2} \mathrm{O}_{3}$ in tension.

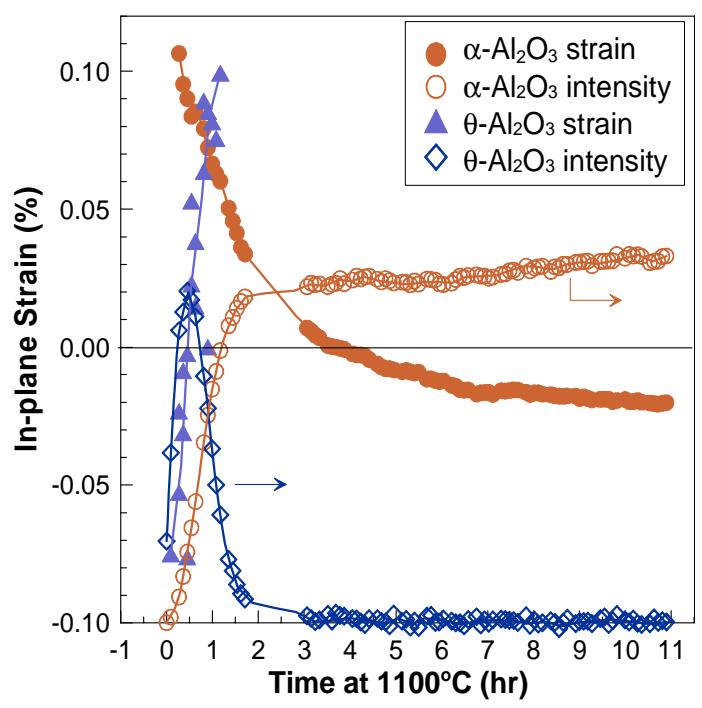

Figure 3: Development of strains and intensities of $\alpha$ - and $\theta-\mathrm{Al}_{2} \mathrm{O}_{3}$ on $\mathrm{Ni}-55 \mathrm{Al}$ at $1100^{\circ} \mathrm{C}$.

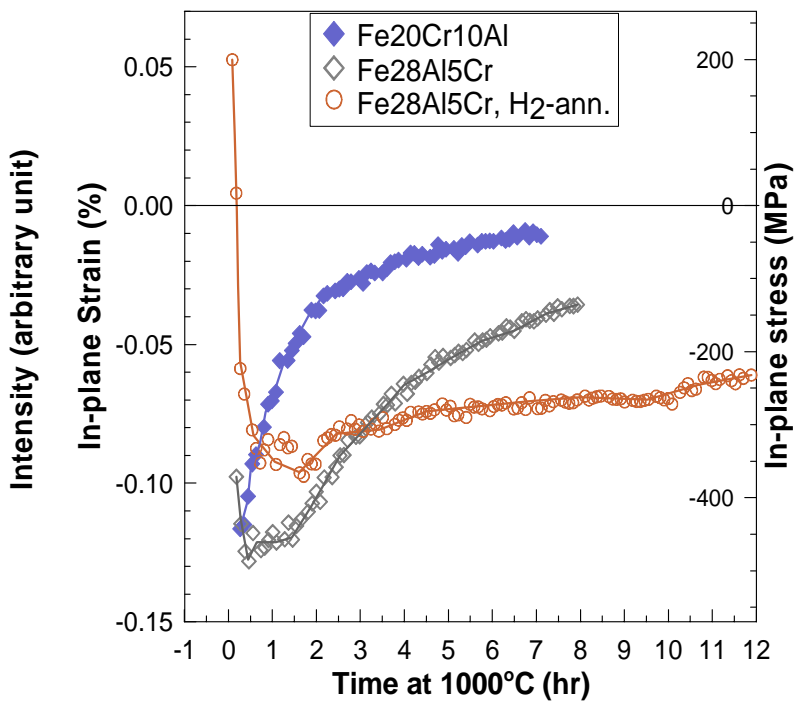

Figure 4: Strain evolution in $\alpha-\mathrm{Al}_{2} \mathrm{O}_{3}$ formed on $\mathrm{Fe}-20 \mathrm{Cr}-10 \mathrm{Al}$, $\mathrm{Fe}-28 \mathrm{Al}-5 \mathrm{Cr}$ and $\mathrm{H}_{2}-$ annealed $\mathrm{Fe}-28 \mathrm{Al}-5 \mathrm{Cr}$ at $1000^{\circ} \mathrm{C}$.

The strain evolution in $\alpha-\mathrm{Al}_{2} \mathrm{O}_{3}$ formed on a $\mathrm{Ni}-55 \mathrm{Al}$ alloy at $1100^{\circ} \mathrm{C}$ is shown in Figure 3; also plotted are the strain evolution in $\theta-\mathrm{Al}_{2} \mathrm{O}_{3}$, and the $\theta$ and $\alpha-\mathrm{Al}_{2} \mathrm{O}_{3}$ intensities. Time zero was taken as the time when temperature reached $1100^{\circ} \mathrm{C}$ from a heating rate of $1000^{\circ} \mathrm{C} / \mathrm{hr}$. The strain for $\alpha-\mathrm{Al}_{2} \mathrm{O}_{3}$ is an average of the values determined from its (116), (024) and (113) rings, and that for the $\theta-\mathrm{Al}_{2} \mathrm{O}_{3}$ is from its (002) and (112) reflections. The theta rings were heavily textured, indicating preferred growth orientation, but the alpha rings were not. The intensities 
are not normalized, so the trend, instead of the magnitude, should be used to indicate the development of different alumina phases in the growing oxide.

It is clear from Fig. 3 that the first-formed scale, which mainly developed during heating, was theta alumina and it was under compression. Using a Young's modulus of $241 \mathrm{GPa}$ [22], the maximum strain corresponds to a stress level of $-193 \mathrm{MPa} . \alpha-\mathrm{Al}_{2} \mathrm{O}_{3}$ later developed and the first-formed alpha was in tension, indicating that this $\alpha-\mathrm{Al}_{2} \mathrm{O}_{3}$ formed mainly by phase transformation and is under tension due to the volume contraction associated with this transformation. With $\mathrm{E}=380 \mathrm{GPa}$, the maximum tensile stress is $418 \mathrm{MPa}$ and is sufficiently high to cause fracture in an aluminum oxide with less than $1 \mu \mathrm{m}$ grain size [23].

With oxidation time, the initial compressive strain in $\theta-\mathrm{Al}_{2} \mathrm{O}_{3}$ and the tensile strain in $\alpha$ $\mathrm{Al}_{2} \mathrm{O}_{3}$ quickly decreased toward zero as the transformation progressed. However, since the tensile state of $\alpha-\mathrm{Al}_{2} \mathrm{O}_{3}$ is maintained by surrounding $\theta-\mathrm{Al}_{2} \mathrm{O}_{3}$, it must be that, at a sufficiently advanced stage of the transformation, both the $\theta-\mathrm{Al}_{2} \mathrm{O}_{3}$ and $\alpha-\mathrm{Al}_{2} \mathrm{O}_{3}$ will be in tension. That is, the reduced volume of the constrained oxide must eventually leave both phases in tension. This behavior is observed in Fig. 3. It is also seen in Fig. 3 that a compressive stress builds in $\alpha$ $\mathrm{Al}_{2} \mathrm{O}_{3}$ long after the $\theta-\mathrm{Al}_{2} \mathrm{O}_{3}$ has transformed (after $\sim 2 \mathrm{hrs}$ ). This must result from a compressive growth stress associated with the thickening of $\alpha-\mathrm{Al}_{2} \mathrm{O}_{3}$. In order to establish a steady state compressive stress, this compressive growth mechanism must be sufficiently fast to overcome any relaxation, which acts to drive the stress to zero. As shown in the next section, relaxation in $\alpha-\mathrm{Al}_{2} \mathrm{O}_{3}$ is significant at $1100^{\circ} \mathrm{C}$. It is also possible that the rate of growth stress generation can change with time, or with scale microstructure.

Results similar to those shown in Fig. 3 have been found on other compositions of $\beta$-NiAl $[16,24]$ at $1100^{\circ} \mathrm{C}$ as well as at $1000^{\circ} \mathrm{C}$, except that the transformation rate is much slower at the lower temperature. The tensile stress seen in $\alpha-\mathrm{Al}_{2} \mathrm{O}_{3}$ at the early stage of oxidation is of the same level as that reported by Tortorelli et al [9], and the low level of steady state stress also agrees well with prior reports on the development of growth stresses in $\alpha-\mathrm{Al}_{2} \mathrm{O}_{3}$ scales $[8,9]$.

The transformation from transition alumina to $\alpha-\mathrm{Al}_{2} \mathrm{O}_{3}$ is faster on $(\mathrm{Fe}, \mathrm{Cr})$-based alloys, than on Ni-based alloys, hence the time at which $\alpha-\mathrm{Al}_{2} \mathrm{O}_{3}$ is under tension is shorter (and, in some cases, may never become tensile). This rapid transformation behavior is illustrated in Fig. 4 with a $\mathrm{Fe}-20 \mathrm{Cr}-10 \mathrm{Al}$ alloy and a $\mathrm{Fe}_{3} \mathrm{Al}$-based alloy containing 5 at\% $\mathrm{Cr}$. The transformation was completed within $1 \mathrm{hr}$ even at an oxidation temperature $100^{\circ} \mathrm{C}$ lower than that shown in Fig. 3 for NiAl. Although it has been reported that higher aluminum concentration slows down the transformation [25], our initial results on a $\mathrm{Fe}-40 \mathrm{Al}$ alloy tested at $1000^{\circ} \mathrm{C}$ [24] still showed a faster rate than that on $\mathrm{Ni}-40 \mathrm{Al}$ at $1100^{\circ} \mathrm{C}$ (see Fig. 5). The ease of $\alpha-\mathrm{Al}_{2} \mathrm{O}_{3}$ development on $\mathrm{Fe}$ and $\mathrm{Fe}+\mathrm{Cr}$ based alloys is believed to be due to the presence of $(\mathrm{Fe}, \mathrm{Cr})_{2} \mathrm{O}_{3}$ that formed during heating, which act as templates for $\alpha-\mathrm{Al}_{2} \mathrm{O}_{3}$ nucleation [26]. Corundum type $(\mathrm{Fe}, \mathrm{Cr})_{2} \mathrm{O}_{3}$ phases were indeed detected by the X-rays on these alloys. Furthermore, TEM studies have shown that the fine-grained scale that formed during the early stage on a FeCrAl alloy with similar composition as the one tested here [18] and on the Cr-containing $\mathrm{Fe}_{3} \mathrm{Al}$ [27] also contain fine $\alpha$ $\mathrm{Al}_{2} \mathrm{O}_{3}$ crystallites.

Effect of $\mathbf{H}_{2}$-anneal. The results in Fig. 4 also show the effect of a hydrogen anneal on the stress development of a $\mathrm{Fe}_{3} \mathrm{Al}$-based alloy. The heat treatment was done in dry $\mathrm{H}_{2}$ at $1200^{\circ} \mathrm{C}$ for $100 \mathrm{hrs}$ on pieces of the $\mathrm{Fe}_{3} \mathrm{Al}$ alloy to remove non-metallic impurities, especially sulfur [28]. The sulfur content in the alloy after the heat treatment dropped from $28 \mathrm{ppm}$ to $0.4 \mathrm{ppm}$. Consequently, there was no observable $\mathrm{S}$ segregation at the $\mathrm{Al}_{2} \mathrm{O}_{3}$ /alloy interface and scale adhesion was significantly improved with an increase of the interface energy by nearly a factor of 20 [28]. The untreated alloy developed scales that were often buckled and spalled extensively upon cooling, but the scale on the $\mathrm{H}_{2}$-annealed sample was flat and remained adherent (Fig. 5(a) and (b)). The stress evolution at $1000^{\circ} \mathrm{C}$, seen in Fig. 4 after the $\mathrm{Al}_{2} \mathrm{O}_{3}$ transformation was 
complete (>1-2 hrs), clearly reflected this morphological difference, indicating that buckling occurred at the oxidation temperature. Since buckling is an effective stress relief mechanism, compressive stresses decreased much faster in the buckled scale than in the flat one. Although the flat scale on the $\mathrm{H}_{2}$-annealed sample retained a higher level of compressive stress during oxidation, there was still some degree of stress relaxation with time. This is believed to be due to relaxation processes in the oxide, as will be discussed in the next section.
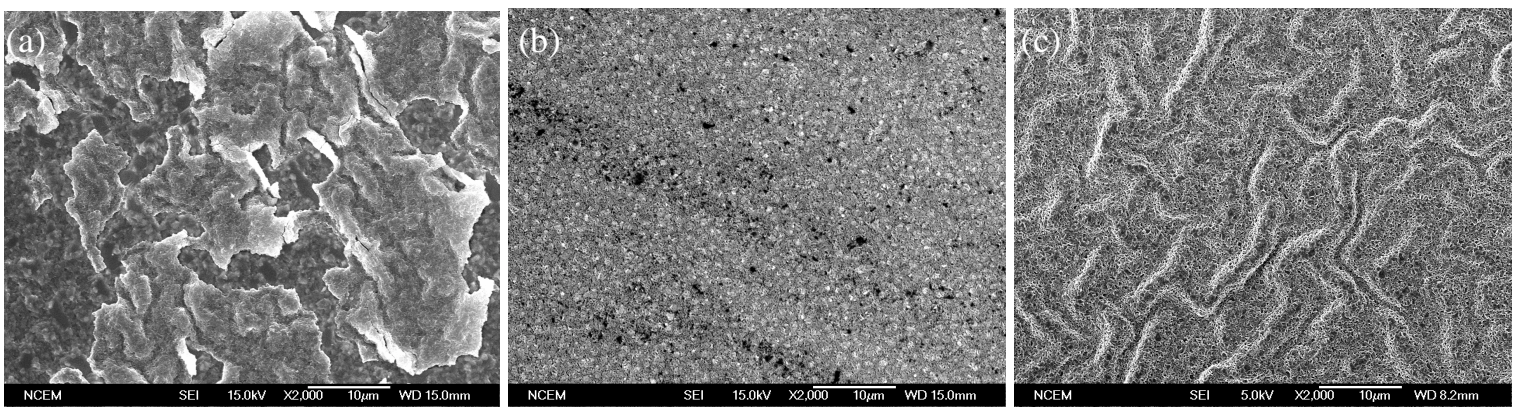

Figure 5: SEM micrographs of the scale formed on (a) the untreated and (b) the $\mathrm{H}_{-2}$-annealed Fe-28Al$5 \mathrm{Cr}$ alloy, and on (c) Fe-20Cr-10Al, after oxidation at $1000^{\circ} \mathrm{C}$ in air for 8, 12 and 7 hours respectively.

With or without $\mathrm{H}_{2}$-anneal, the stress level in $\alpha-\mathrm{Al}_{2} \mathrm{O}_{3}$ on the Fe-28Al-5Cr samples quickly turned from $\sim 200 \mathrm{MPa}$ tension in the first hour, due to the transition alumina to $\alpha-\mathrm{Al}_{2} \mathrm{O}_{3}$ transformation, to 350-450 $\mathrm{MPa}$ compression. The maximum compressive stress in the $\mathrm{H}_{2}$ annealed sample was 100-120 MPa lower than that in the untreated alloy. This could be due to a lower growth stress associated with the thickening of the $\alpha-\mathrm{Al}_{2} \mathrm{O}_{3}$ or to a slower transformation rate from transition to alpha alumina. In any case, the $\mathrm{H}_{2}$-anneal did not sufficiently alter the magnitude of the growth stresses to significantly affect adhesion. The improved adhesion, therefore, must be provided by the cleaner, sulfur-free, interface [28].

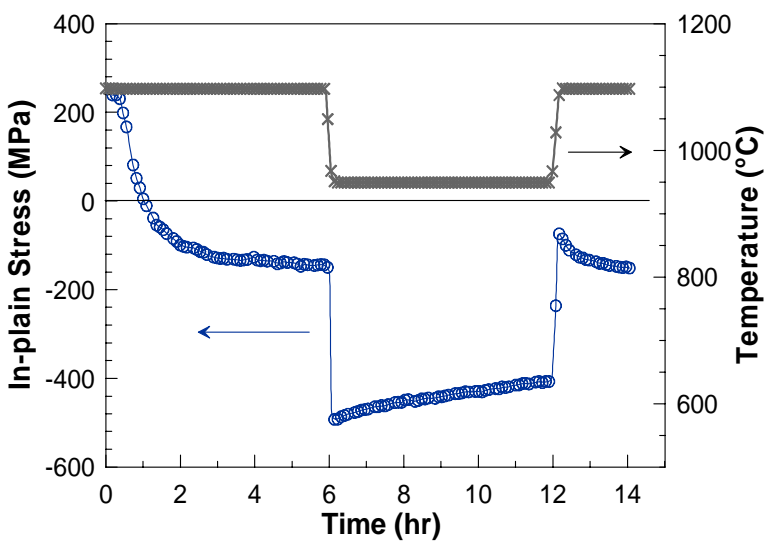

Figure 6: Relaxation of thermally induced stress at $950^{\circ} \mathrm{C}$ in $\alpha-\mathrm{Al}_{2} \mathrm{O}_{3}$ on $\mathrm{Ni}-40 \mathrm{Al}$ oxidized at $1100^{\circ} \mathrm{C}$.

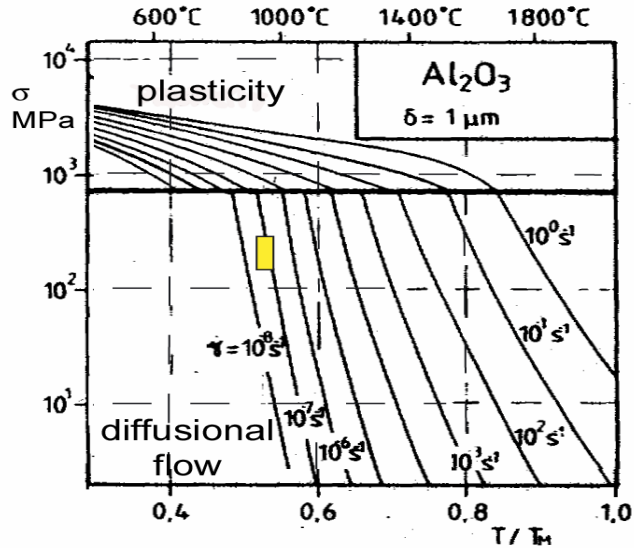

Figure 7: Experimentally determined strain rates (boxed) in relation to a deformation map adopted from [30] for $1 \mu \mathrm{m} \mathrm{Al}_{2} \mathrm{O}_{3}$.

Stress relaxation during oxide growth. Of all the examples shown so far, the growth stresses in the first-formed oxide layer are seen to be highly compressive, or tensile if there is a volume reduction associated with phase transformation, but the levels always relaxed to relatively low steady state values between -(150-220) MPa. We believe this steady state level is a result of equilibrium between the stress generation and relaxation processes. For the $\mathrm{Cr}-$ containing $\mathrm{Fe}_{3} \mathrm{Al}$, the relaxation is achieved by scale buckling, as discussed earlier. For the Fe$20 \mathrm{Cr}-10 \mathrm{Al}$, stress relaxation from the maximum initial compression of $\sim 430 \mathrm{MPa}$ is even faster than on the $\mathrm{Fe}_{3} \mathrm{Al}$ alloy, and is believed to be associated with scale wrinkling (Fig. 5(c)), where 
the alloy and the scale corrugated together [24] over the entire sample surface. Apparently, this process is even more effective in reducing the compressive stress than local buckling. Of course, there may also be differences in the rate of growth internal to the oxides, which will affect relaxation rates and the steady state stress levels. On the $\mathrm{NiAl}$ and the $\mathrm{H}_{2}$-annealed $\mathrm{Fe}_{3} \mathrm{Al}$, although the scales remained flat and adherent, the steady-stage stress level was low and stress relaxation was still observed. To study the rate of stress relaxation on adherent scales, some test samples were first oxidized at $1100^{\circ} \mathrm{C}$ for $6-7$ hours and then quickly cooled to $950^{\circ} \mathrm{C}$. This temperature drop induces a compressive stress in the scale from the thermal expansion mismatch between the oxide and the alloy. Stress levels in the oxide were continuously followed for 3 to 4 hours at $950^{\circ} \mathrm{C}$ before returning the temperature to $1100^{\circ} \mathrm{C}$. Figure 6 gives an example of such a test, where the imposed thermal stress is seen to gradually decrease with time at $950^{\circ} \mathrm{C}$.

The strain rates determined from the relaxation seen in Fig. 6 and on other similarly tested samples are given in Table 1 . The fact that strain rates are all close to $1 \times 10^{-8} / \mathrm{s}$ regardless of the substrate grain size and thickness indicates that most of the relaxation is achieved in the oxide. Furthermore, since $\sigma_{\mathrm{m}}=\sigma_{\mathrm{ox}}\left(2 \mathrm{~h}_{\mathrm{ox}} / \mathrm{h}_{\mathrm{m}}\right)$, where $\sigma$ 's are the stresses and h's the thicknesses of the metal and the oxide, the maximum stress level in the $3.5 \mathrm{~mm} \mathrm{Ni}-40 \mathrm{Al}$ with a scale thickness of 1 $\mu \mathrm{m}$ under the present oxidation condition would only be $0.2 \mathrm{MPa}$, which is too low to cause any deformation in $\mathrm{NiAl}$ [29]. According to a deformation map formulated for $1 \mu \mathrm{m} \mathrm{Al}_{2} \mathrm{O}_{3}$ [30], the strain rate in the range of our applied stresses at $950^{\circ} \mathrm{C}$ (box in Fig. 7) should be between $10^{-7}$ $10^{-8} / \mathrm{s}$, which agrees fairly well with the rates obtained here. Extrapolations from higher temperature measurements, obtained from deformation studies of fine-grained $\mathrm{Al}_{2} \mathrm{O}_{3}[31,32]$, give strain rates at $950^{\circ} \mathrm{C}$ of about $10^{-8} / \mathrm{s}$, which again agrees well with our results. It therefore seems quite certain that the stress relaxation is achieved by processes that take place in the oxide, probably by diffusional creep. The exact mechanism, however, is not yet clear. The deformation mechanism is usually determined from the stress dependence of the strain rate. In our case, the data can be fitted with a stress exponent of 1 or 2, indicating oxide creep or some degree of grain boundary sliding [33].

Table 1: Summary of strain rates at $950^{\circ} \mathrm{C}$ under -(500-260) MPa compressive stress. The rates are obtained by monitoring the change in strains in the $\alpha-\mathrm{Al}_{2} \mathrm{O}_{3}$ layer.

\begin{tabular}{l|l|l}
\hline Specimen Description & $\begin{array}{l}\text { Specimen } \\
\text { Thickness }(\mathrm{mm})\end{array}$ & $\begin{array}{l}\text { Calculated } \\
\text { Strain Rate }\left(\mathrm{s}^{-1}\right)\end{array}$ \\
\hline Ni-40Al, poly-crystal, average grain size $\sim 590 \mu \mathrm{m}$ & 1 & $1.33 \times 10^{-8}$ \\
& 3.5 & $1.17 \times 10^{-8}$ \\
\hline Ni-50Al, single crystal & 1.4 & $1.46 \times 10^{-8}$ \\
\hline
\end{tabular}

Conclusions. In-situ x-ray diffraction measurements, exploiting synchrotron radiation and making use of Debye-Sherrer diffraction rings from a range of $\psi$ angles, between $7-75^{\circ}$, have been used to follow precisely the growth strains in $\mathrm{Al}_{2} \mathrm{O}_{3}$ scales thermally grown on model alloys. When transition aluminas are detectable, volume contraction from the transformation of transition alumina to the alpha form puts the initially formed $\alpha-\mathrm{Al}_{2} \mathrm{O}_{3}$ in high tension. This transformation process is accelerated by the presence of $(\mathrm{Fe}, \mathrm{Cr})_{2} \mathrm{O}_{3}$ that formed during heating on $\mathrm{Fe}$ and $\mathrm{Fe}+\mathrm{Cr}$ alloys, as these oxides serve as templates that enhance $\alpha-\mathrm{Al}_{2} \mathrm{O}_{3}$ nucleation. With this accelerated transformation, tensile stresses may not develop. The first formed transition aluminas, when observable, appear in high compression, about several hundred MPa, which quickly relaxes within a few hours at the oxidation temperature $\left(1000-1100^{\circ} \mathrm{C}\right)$. Depending on substrate composition, the first $\alpha-\mathrm{Al}_{2} \mathrm{O}_{3}$ may be in high tension, or in compression. These stresses relax toward a steady state that is controlled by competing internal growth and relaxation processes that take place in the fine-grained oxide. For some substrate 
compositions, part of the relaxation can be due to scale decohesion and buckling, as on a Crcontaining $\mathrm{Fe}_{3} \mathrm{Al}$, or scale wrinkling on $\mathrm{Fe}-20 \mathrm{Cr}-10 \mathrm{Al}$, and part due to oxide deformation. $\mathrm{H}_{2}-$ annealing of the $\mathrm{Cr}$-containing $\mathrm{Fe}_{3} \mathrm{Al}$ alloy greatly reduces the alloy sulfur content and improved scale adhesion, but did not have a large effect on $\mathrm{Al}_{2} \mathrm{O}_{3}$ phase transformation or oxide stress development. Scale adhesion, therefore, must be dominated by the interface chemistry.

\section{Acknowledgment}

The authors would like to thank Dr. James Smialek for the $\mathrm{H}_{2}$-anneal. This research is sponsored by the U. S. Department of Energy, BES, Materials Science, under contracts Nos. DE-AC03-76SF00098 and W-31-109-ENG-38.

\section{References}

[1] N. B. Pilling and R. E. Bedworth, J. Inst. Met. Vol. 29 (1923), p. 529

[2] F. N. Rhines and J. S. Wolf, Metall. Trans., Vol. 1 (1970), p. 1701

[3] See for example the review by J. Stringer, Corr. Sci., Vol. 10 (1970), p.513

[4] D. Delaunary, A. M. Huntz and P. Lacombe, Corr. Sci., Vol. 20 (1980), p.1109

[5] S. R. J. Saunders, H. E. Evans, M. Li, D. D. Gohil and S. Osbergy, Oxid. Met., Vol. 48 (1997), p.189

[6] Meishuan Li, Tiefan Li, Wei Gao and Zhenyu Liu, Oxid. Met., Vol. 51 (1999), p.333

[7] N. Eisenreich, H. Fietzek, M.J. Garcia-Vargas, M. Juez-Lorenzo and V. Kolarik, J. Corr. Sci. Eng., Vol. 6 (2003), paper H062

[8] E. Schumann, C. Sarioglu, J. R. Blachere, F. S. Pettit and G. H. Meier, Oxid. Met., Vol. 53 (2000), p.259

[9] P. F. Tortorelli, K. L. More, E. D. Specht, B. A. Pint and P. Zschack, Mater. High Temp., Vol. 30 (2003), p. 303

[10] H. E. Evans, Mater. Sci. Eng. A, Vol. A203 (1995), p.117

[11] I .C. Noyen and J. B. Cohen, Residual stress measurement by diffraction and interpretation, (Springer-Verlag, New York, 1987).

[12] The Oxide Handbook, Second Edition, p. 183, ed. G. V. Samsonov, IFI/Plenum, New York, 1982.

[13] J. Doychak, J. L. Smialek and T. E. Mitchell, Met. Trans. Vol 20A (1989), p. 499

[14] G. C. Rybicki and J. L. Smialek, Oxid. Metals, Vol. 31 (1989), p. 275

[15] V. K. Tolpygo and D. R. Clarke, Mater. High Temp., Vol. 17 (2000), p. 59

[16] P. Y. Hou, A. P. Paulikas and B. W. Veal, Microscopy of Oxidation, April 4-6, 2005, University of Birmingham, UK, to be published in Mater. High Temp.

[17] J. C. Yang, K. Nadarzinski, E. Schumann and M. Rühle, Scripta Met., Vol. 33 (1995), p. 1043

[18] A. Andoh, S. Taniguchi and T. Shibata, Mater. Sci. Forum, Vol. 369-372 (2001), p. 303

[19] H. El Kadiri, R. Molins and Y. Bienvenu, Mater. Sci. Forum, Vol. 461-464 (2004), p. 1107

[20] M. W. Brumm and H. J. Grabke, Corr. Sci., Vol. 33 (1992), p. 1677

[21] R. Prescott, D. F. Mitchell and M. J. Graham, Corr., Vol. 50 (1994), p. 62

[22] C. Li, A. Ohmori and R. McPherson, J. Mater. Sci., Vol. 32 (1997), p. 997

[23] M. Schutze, Proc. workshop high temperature corrosion of advanced materials and protective coatings, p. 39, (Elsevier Sci. Pub. 1992).

[24] P. Y. Hou, A. P. Paulikas and B. W. Veal, Mater. Sci. Forum, Vol.461-464 (2004), p. 671

[25] Z. G. Yang and P. Y. Hou, Mater. Sci. Eng. A, Vol. 391 (2005), p. 1

[26] D. Renusch, M. Grimsditch, I. Koshelev, B. W. Veal and P. Y. Hou, Oxid. Met., Vol. 48 (1997), p. 471

[27] X. F. Zhang, K. Thaidigsmann, J. Ager, and P. Y. Hou, "Initial stage $\mathrm{Al}_{2} \mathrm{O}_{3}$ scale development on a Cr-containing iron aluminide", manuscript in preparation.

[28] P. Y. Hou and J. L. Smialek, Mater. High Temp., Vol. 17 (2000), p. 79

[29] E. Arzt and P. Grahle, Acta mater., Vol. 46 (1998), p. 2717

[30] M. Schutze, Mater. Sci. Tech., Vol. 6 (1990), p. 32

[31] R. M. Cannon, W. H. Rhodes and A. H. Heuer, J. Am. Cerem. Soc., Vol. 63 (1980), p. 46

[32] H-T. Lin and P. F. Becher, J. Am. Cerem. Soc., Vol. 73, (1990), p. 1378

[33] W. D. Kingery, H. K. Bowen and D. R. Uhlmann, Introduction to Ceramics, second edition, p. 736, Wiley-Interscience, New York, 1975. 